\title{
Formation of nanoscale tungsten oxide structures and colouration characteristics
}

\author{
VIJAY BHOOSHAN KUMAR and DAMBARUDHAR MOHANTA* \\ Nanoscience Laboratory, Department of Physics, Tezpur University, Tezpur 784 028, India
}

MS received 1 September 2010; revised 6 December 2010

\begin{abstract}
In this work, $\mathrm{pH}$ dependent evolution of tungsten oxide $\left(\mathrm{WO}_{3}\right)$ nanostructures is being reported along with physical characteristics. The synthesis was carried out via an inexpensive solvothermal cum chemical reduction route, with sodium tungstate $\left(\mathrm{Na}_{2} \mathrm{WO}_{4}\right)$ and cetyl trimethyl ammonium bromide $\left(\mathrm{C}_{19} \mathrm{H}_{42} \mathrm{NBr}\right)$ as main reactants. The X-ray diffraction, together with transmission electron microscopic studies have revealed formation of regular polyhedral nanocrystalline structures and fractals as one goes from higher $\mathbf{p H}(=5.5)$ to lower $\mathbf{p H}(=2)$ values. The average crystallite size, as calculated through Williamson-Hall plots, was varied within 2.8-6.8 nm for different pH samples. Fourier transform infrared spectroscopy reveals in-plane bending vibration $\delta(\mathrm{W}-\mathrm{OH})$, observable at $\sim 1630 \mathrm{~cm}^{-1}$ and strong stretching $v(\mathrm{~W}-\mathrm{O}-\mathrm{W})$ located at $\sim 814 \mathrm{~cm}^{-1}$. Raman spectroscopy has divulged $\mathrm{WO}_{3}$ Raman active optical phonon modes positioned at $\sim 717$ and $805 \mathrm{~cm}^{-1}$. The thermochromic and photochromic properties of the nanoscale $\mathrm{WO}_{3}$ sample prepared at $\mathrm{pH}=5 \cdot 5$, are also highlighted.
\end{abstract}

Keywords. Tungsten oxide; nanoparticles; photochromic; thermochromic.

\section{Introduction}

The transition elements are characterized by variable oxidation states and that is why they can form a wide variety of stable oxide compounds. Transition metal oxide systems exhibit numerous exciting properties in the arena of superconductivity, colossal magnetoresistance effect, piezoelectricity, microelectronics, photonics, photocatalysis and so on. Tungsten oxide $\left(\mathrm{WO}_{3}\right)$, in particular, is considered as a potential candidate which exhilarates photophysical and photochemical properties (Leland and Bard 1987; Henglein 1989; Hagfeldt and Gratzel 1995; Li et al 1998). Over the years, stoichiometric $\mathrm{WO}_{3}$ of high quality has emerged as a potential candidate in electrochromic (Granqvist 2000), photochromic (Sun et al 2000), thermochromic, gasochromic and lithium battery (Lee et al 2003) applications. Typically, $\mathrm{WO}_{3}$ is a technologically important wide bandgap $(\sim 2.8 \mathrm{eV})$ oxide semiconductor system and recently it was shown that energy gap feature can be adequately varied with nitrogen doping content (Lethy et al 2009).

Along with very high thermal and electrical conductivities, pure tungsten $(\mathrm{W})$ and $\mathrm{WO}_{3}$ have superior thermal stability and therefore, can withstand very high temperature. Over the decades, metallic $\mathrm{W}$ is widely used as a thermionic cathode material (Wang et al 2002; Selcuk et al 2004) as an electrical contact material (Kang 2004), as a raw material for ultrahard alloys in high-speed steels, cutting tools,

\footnotetext{
*Author for correspondence (best@ tezu.ernet.in)
}

and anti-friction tools (Bailar and Emeleus 1973). In contrast, $\mathrm{WO}_{3}$ offers plentiful applications in smart windows, large area displays, field emission (Agiral and Gardeniers 2008), catalysis (Engweiler et al 1996), and reducing gas pollutants (Madou and Morrison 1989; Jimenez et al 2003). In view of adequate surface functionality and quantum size effect, nanoscale $\mathrm{WO}_{3}$ is expected to play a key role in the foremost technological assets. In addition, stoichiometric $\mathrm{WO}_{3-x}$ nanostructures offer fundamental opportunities for investigating the effect of size, shape and dimensionality on their collective optical, magnetic, and electronic properties. Earlier, it was demonstrated that stoichiometric $n$-type oxide semiconductor (Noh et al 2002) like $\mathrm{WO}_{3}$ can act as gas sensing (Lee et al 2000) element that can be employed for reducing gas pollutants $\left(\mathrm{NH}_{3}, \mathrm{H}_{2} \mathrm{~S}, \mathrm{NO}_{x}\right.$ etc). Also, it was shown that a minimal inclusion of $\mathrm{TiO}_{2}$ into $\mathrm{WO}_{3-x}$ $(0<x<1)$ can help in suppressing recombination of photogenerated carriers, thus inducing reversible colouration phenomena (He et al 2002). However, $\mathrm{pH}$ dependent structural evolution aspect of this system is rarely found in the literature. The present work describes a solvothermal-cumreduction route, nanoscale $\mathrm{WO}_{3}$ structural evolution and thermally and optically induced colouration phenomena of the product.

\section{Experimental}

Nanoscale $\mathrm{WO}_{3}$ structures were fabricated as described below. In two separate flasks, $1.5 \mathrm{~g}$ of sodium tungstate 


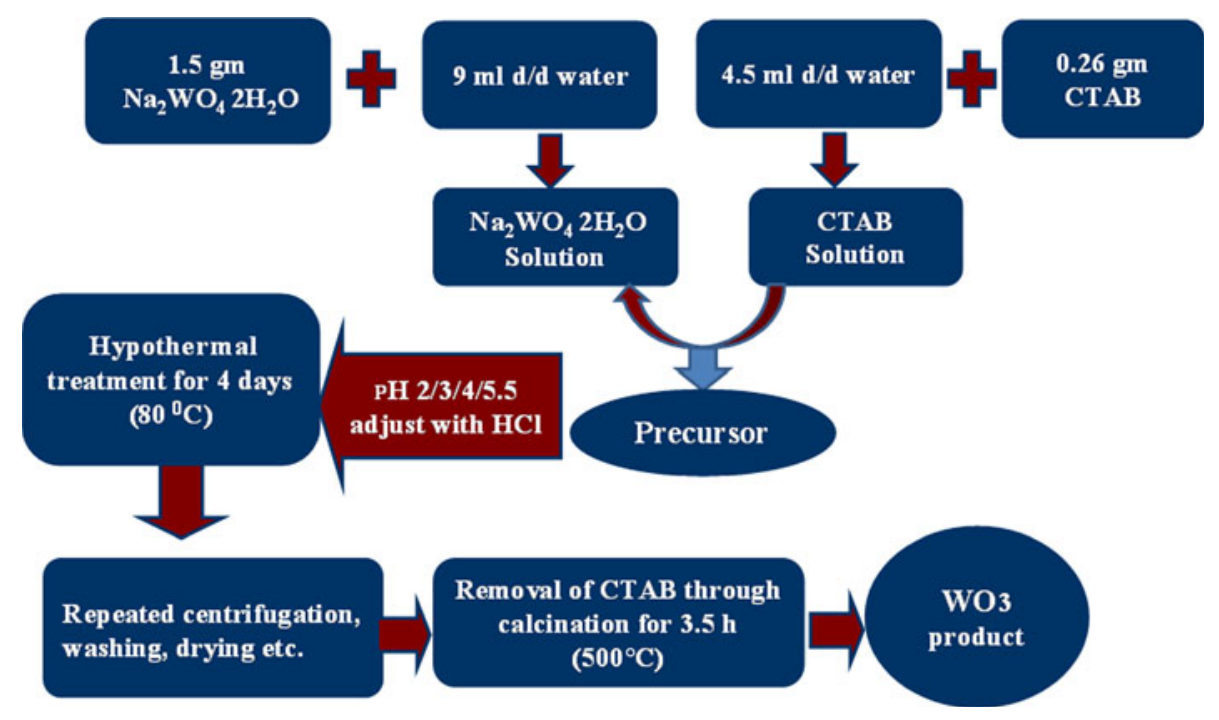

Figure 1. Block diagram for synthesizing nanoscale $\mathrm{WO}_{3}$ products.

dihydrate $\left(\mathrm{Na}_{2} \mathrm{WO}_{4} \cdot 2 \mathrm{H}_{2} \mathrm{O}\right.$, Merck, $99.99 \%$ pure $)$ was dissolved in $9 \mathrm{ml}$ of distilled water while $0.26 \mathrm{~g}$ cetyl-trimethyl ammonium bromide (CTAB) $\left(\mathrm{C}_{19} \mathrm{H}_{42} \mathrm{NBr}, \mathrm{CDH}, 99.99 \%\right.$ pure), a cationic surfactant was suspended in $4.5 \mathrm{ml}$ of distilled water. The aq. CTAB was then dropwise injected to the aq. sodium tungstate solution under constant magnetic stirring. While making separate precursors in four test tubes, the $\mathrm{pH}$ value was adjusted to $2 \cdot 0,3 \cdot 0,4 \cdot 0$ and $5 \cdot 5$ using $2 \mathrm{M} \mathrm{HCl}$. The basic idea behind $\mathrm{pH}$ variation was to study structural and morphological evolution along with variation of crystallite size. For slow but progressive reaction, the test tubes were sealed and then submerged into a water bath at $80^{\circ} \mathrm{C}$ for 4 days. The resulting precipitates were recovered by repeated centrifugation and washing with distilled water. As received products were then subjected to oven drying at $160^{\circ} \mathrm{C}$ for $2 \mathrm{~h}$. Knowing that CTAB has a m.p. of $\sim 270^{\circ} \mathrm{C}$, and in order to remove unwanted impurities along with $\mathrm{CTAB}$, each of the products was calcined at $500^{\circ} \mathrm{C}$ for $3.5 \mathrm{~h}$. Note that $\mathrm{pH}>7$ did not result in adequate precipitation and thus subsequent experimentation was difficult when the precursor was made alkaline. A block diagram highlighting systematic synthesis steps is presented in figure 1 .

The synthesized products were characterized by X-ray diffraction (XRD, Miniflex, Rigaku), UV-Visible optical absorption spectroscopy (UV-2450, Shimadzu Corporation), Fourier transform infrared (FT-IR, Nicolet Impact I-410) spectroscopy, and transmission electron microscopy (TEM, JEM-100 CX II). Micro-Raman (LabRam HR800 Raman Spectrometer, HORIBA Jobin Yvon) experiments were carried out by using an $\mathrm{Ar}^{+}$ion laser (Power $=2 \mathrm{~mW}, \lambda=$ $514.5 \mathrm{~nm}$, beam spot diameter, $\sim 10 \mu \mathrm{m})$ as the excitation source. It is expected that such a low power would not cause excessive heating and unwanted thermal interference. The exposure and data acquisition times were 10 and $2 \mathrm{~s}$, respectively while the spectral resolution was fixed at
$0.6 \mathrm{~cm}^{-1}$. Finally, photochromic and thermochromic studies were performed on the nanoscale $\mathrm{WO}_{3}$ product prepared at $\mathrm{pH}=5 \cdot 5$.

\section{Results and discussion}

The results of X-ray diffraction, electron microscopy and spectroscopy studies on the synthesized products are presented below. The colouration phenomena activated by thermal and optical means are also discussed.

\section{$3.1 \quad X$-ray diffraction analysis}

XRD study was performed to explore the crystal structure and preferred orientation of the crystallites that make up a definite nanostructure. Figure 2 shows the characteristic XRD patterns of nanoscale $\mathrm{WO}_{3}$ products obtained for $\mathrm{pH}$ values: $2 \cdot 0,3 \cdot 0,4 \cdot 0$, and $5 \cdot 5$. The main peaks in the diffractograms are indexed as (002), (020), (200), (120), (112), (022), (202), (222) and (140) corresponding to Bragg's angles $2 \theta=23 \cdot 17,23 \cdot 66,24 \cdot 38,26 \cdot 63,28 \cdot 79,34 \cdot 14,35 \cdot 56$, 41.69 , and $50 \cdot 7^{\circ}$. The peak at $2 \theta=55.1$ and $60.8^{\circ}$ corresponded to the $\mathrm{WO}_{2}$ and metallic $\mathrm{W}$ phases, respectively and are prominent for $\mathrm{pH}=5 \cdot 5$. Though traces of other stoichiometric compositions cannot be avoided fully, however, $\mathrm{WO}_{3}$ phase is the most desirable one. Looking at the standard JCPDS data for different phases (shown in the bottom part of figure 2), we ensure that the monoclinic and triclinic phases essentially coexist but to different extents. In fact, the former dominates the later for the sample prepared in less acidic environment. Two remarkable observations can be drawn. First, the gradual emergence of diffraction peaks as one goes from $\mathrm{pH}=2$ to $5 \cdot 5$. Second, out of the closely spaced 


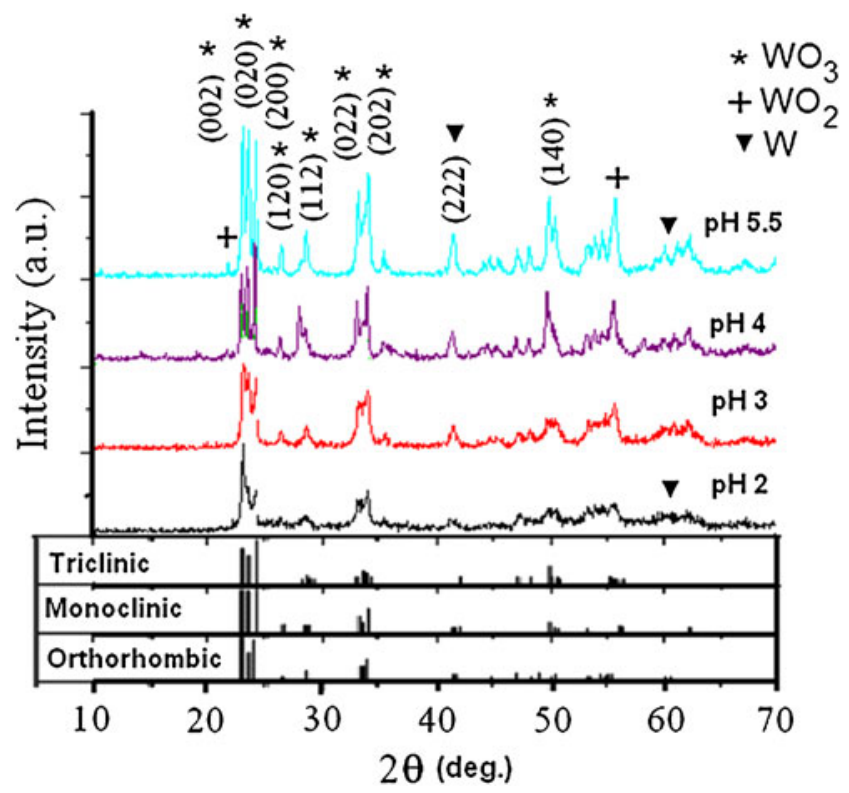

Figure 2. XRD patterns of tungsten oxide nanoparticles synthesized at different $\mathrm{pH}$ values.

peaks, (200) peak gets suppressed for $\mathrm{pH}=2$. This observation has led us to realize that in the process of nanostructure formation, definite planes (e.g. (200) in this case) of growth are affected by the $\mathrm{pH}$ environment. In the case of $\mathrm{pH}=5 \cdot 5$, the crystallites having competitive orientation along (002) (020) (200) were preferred. Conversely, corresponding to a more acidic environment $(\mathrm{pH}=2)$, the preferred orientation is clearly along (002) plane. The average crystallite size $(d)$ and microstrain $(\varepsilon)$ were estimated from Williamson-Hall plots using the relation (Williamson and Hall 1953):

$$
\beta \cos \theta=0.9 \lambda / d+4 \varepsilon \sin \theta .
$$

Here, $\beta$ is the full width at half maxima of the corresponding peak at the Bragg's diffraction angle $2 \theta$. The results are presented in table 1 . As can be seen a change of $\mathrm{pH}$ from $5 \cdot 5$ to 2 has resulted in the drastic variation in the average crystallite size: $\sim 2.8$ to $6.8 \mathrm{~nm}$. The order of microstrain in all of the cases is $\sim 10^{-3}$. The observation of some subsidiary peaks in the main XRD pattern could have arisen due to the occur- rence of other minor by-products (e.g. W, $\mathrm{WO}_{2}, \mathrm{WO}_{3-x}$, $\mathrm{W}_{18} \mathrm{O}_{49}$ etc.) in the final product.

\subsection{UV-Visible absorption studies}

The optical absorption properties of the $\mathrm{WO}_{3}$ nanostructures were studied by UV-visible spectroscopy and the results are presented in figure 3 . The absorption features though appear same, the absorbance was found to be improved while $\mathrm{pH}$ changes through $2 \cdot 0$ to $5 \cdot 5$. Also, with $\mathrm{pH}$ reduction, the onset of absorption is found to get red-shifted slightly giving out an energy gap variation within $2 \cdot 78-3 \cdot 3 \mathrm{eV}$. This is also supported by the XRD data as we notice enhancement of the crystallite size with decrease of $\mathrm{pH}$. Thus, the $\mathrm{WO}_{3}$ nanoparticles are associated with a wide bandgap. Further, the visible broad absorption peaks in all the $\mathrm{pH}$ cases suggest that the distinct $1 s-1 s$ excitonic transitions are rather unlikely. The bulk Bohr exciton radius for $\mathrm{WO}_{3}$ system is $\sim 13 \mathrm{~nm}$. Nevertheless, fundamental absorption for samples (higher $\mathrm{pH}$ ) containing smaller crystallites has been significantly enhanced. Also, transitions associated with upper levels combined with collective absorption process can result in broad peaks.

\subsection{FT-IR spectroscopy studies}

FT-IR spectra gives us information with regard to in plane and out of plane segmental vibration of atoms and/or molecules with associated energies in the infrared regime. The stretching, bending, bonding and wiggling can be predicted through FT-IR measurements. Know that the crystalline structure of $\mathrm{WO}_{3}$ is a three-dimensional adjustment (an oxopolianion) of $\mathrm{WO}_{6}$ octahedra, in which the atoms of $\mathrm{W}$ are located in the centre of the octahedra and oxygen are at the vertices, thus each oxygen is forming a connection W-O-W (Pfeifer et al 1995).

It was previously suggested that the observed absorption bands in the IR-spectra are due to the stretching of connections O-W-O (Hargittai et al 1971; Atanassor et al 1993; Pfeifer et al 1995; Raougier et al 1999). In fact, $\mathrm{WO}_{3}$ consists of packed corner-sharing $\mathrm{WO}_{6}$ octahedra, containing 4 atoms and 6 fundamental normal modes of vibration. The

Table 1. Physical properties of tungsten oxide products obtained from Williamson-Hall plots (using figure 2).

\begin{tabular}{|c|c|c|c|}
\hline Samples & Lattice parameters $(\AA)$ & Microstrain $(\varepsilon)$ & Average crystallite size $(D)$ \\
\hline pH $5 \cdot 5$ & $\begin{array}{c}a=6.98 \pm 0.7 ; \quad b=6.15 \pm 0.7 \\
c=6.5 \pm 0.7\end{array}$ & $1.6 \times 10^{-3}$ & $28.01 \pm 4.6 \AA$ \\
\hline $\mathrm{pH} 4$ & $\begin{array}{c}a=7.02 \pm 0.9 ; \quad b=7.30 \pm 0.9 \\
c=7.45 \pm 0.9\end{array}$ & $1 \cdot 1 \times 10^{-3}$ & $36 \cdot 78 \pm 3 \cdot 6 \AA$ \\
\hline pH 3 & $\begin{array}{c}a=7.12 \pm 0.6 ; \quad b=7.36 \pm 0.9 \\
c=7.75 \pm 0.6\end{array}$ & $1.5 \times 10^{-3}$ & $49 \cdot 34 \pm 5 \cdot 3 \AA$ \\
\hline pH 2 & $\begin{array}{c}a=7.12 \pm 0.7 ; \quad b=7.20 \pm 0.7 \\
c=7.16 \pm 0.7\end{array}$ & $1.7 \times 10^{-3}$ & $68.34 \pm 7.7 \AA$ \\
\hline
\end{tabular}




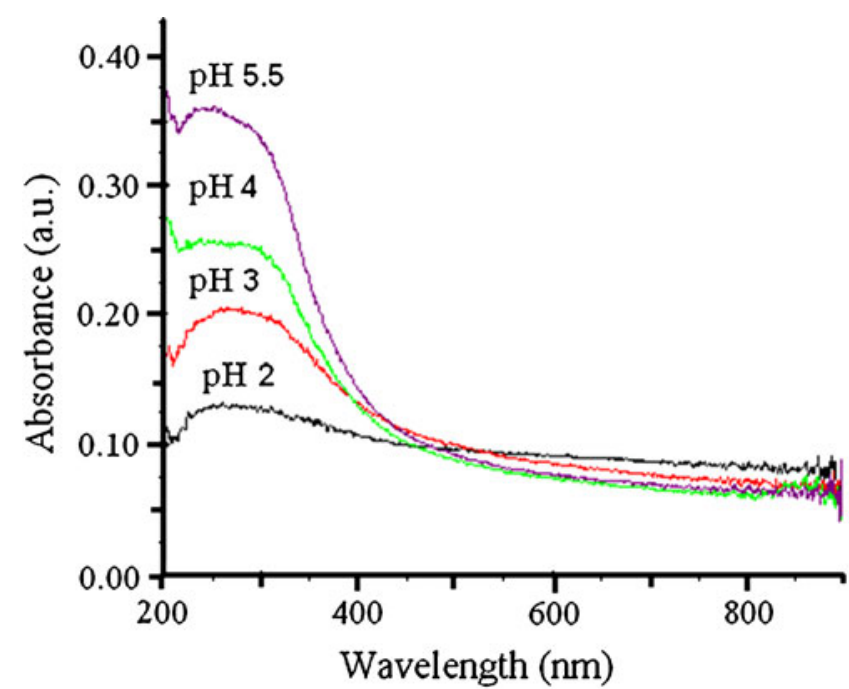

Figure 3. UV-Visible spectra of tungsten oxide nanoparticles synthesized at different $\mathrm{pH}$.

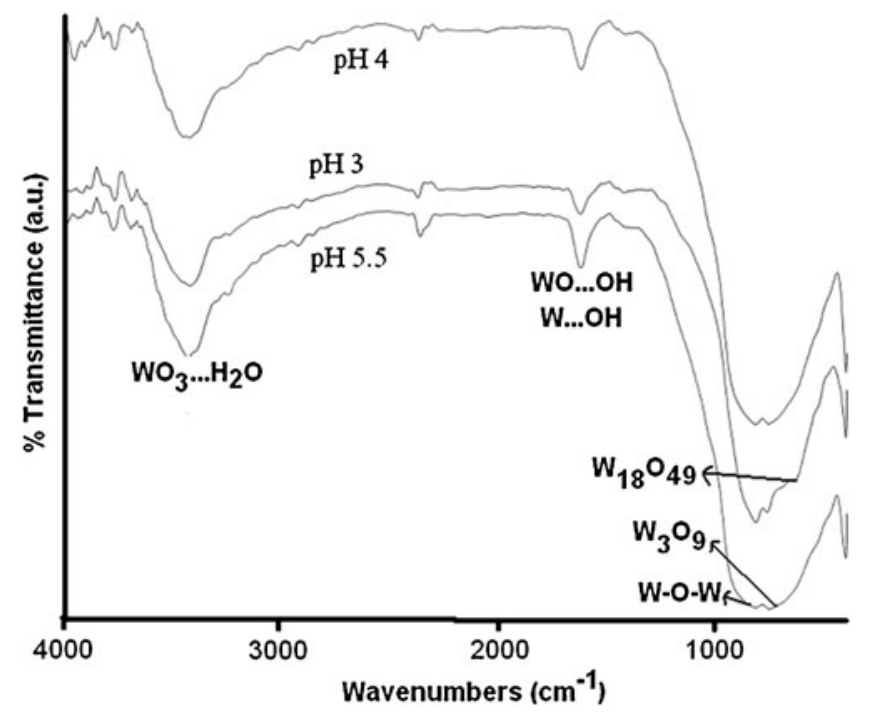

Figure 4. FTIR spectra of tungsten oxide nanoparticles synthesized at different $\mathrm{pH}$.

observed vibration bands are mainly the fundamental vibrations of $\mathrm{W}=\mathrm{O}, \mathrm{W}-\mathrm{O}$ and $\mathrm{W}-\mathrm{O}-\mathrm{W}$ chromophores. The local symmetry of the $\mathrm{W}=\mathrm{O}$ chromophore allows the separation of normal modes according to the direction of their dynamic dipoles, thus helping the assignment of IR active vibrations. For molecular structure and orientation determination, the most relevant normal modes are the stretching vibrations $(v)$, in-plane bending vibrations $(\delta)$ and out-of-plane wagging $(\gamma)$ modes. The FTIR spectra of three representative samples $(\mathrm{pH}=3,4$, and 5.5) are shown in figure 4 and the corresponding assignments are presented in table 2. As can be seen, the symmetric stretching vibrations $\left(v_{\text {sym }}\right)$, related to $\mathrm{WO}_{3}$ and intercalated water molecules $\left(\mathrm{W}-\mathrm{OH} \ldots \mathrm{H}_{2} \mathrm{O}\right)$ is characterized by a prominent peak at $\sim 3450 \mathrm{~cm}^{-1}$. Similarly,
Table 2. Assigned vibrational modes as revealed from FT-IR spectra.

\begin{tabular}{lccc}
\hline Sl. No. & Group & Wavenumbers $\left(\mathrm{cm}^{-1}\right)$ & Assignment \\
\hline 1 & W-OH ... $\mathrm{H}_{2} \mathrm{O}$ & 3454 & $\nu_{\text {sym }}(\mathrm{OH})$ \\
& & 3400 & \\
2 & $\mathrm{O}-\mathrm{H}$ & 3071 & $\nu \mathrm{OH}$ \\
3 & $\mathrm{OH}, \mathrm{H}-\mathrm{O}-\mathrm{H}$ & 1633 & $\delta \mathrm{OH}$ in W-OH \\
& & 1649 & $\delta(\mathrm{OH}-\mathrm{O})$ \\
4 & $\mathrm{OH}, \mathrm{W}-\mathrm{O}$ & 1433 & $\nu \mathrm{OH}, \delta \mathrm{OH}$ \\
5 & $\mathrm{~W}-\mathrm{OH}$ & 1041 & $\delta \mathrm{W}-\mathrm{OH}$ \\
6 & $\mathrm{~W}=\mathrm{O}, \mathrm{W}-\mathrm{O}$ & 962 & $\nu \mathrm{W}_{-} \mathrm{O}$ \\
7 & $\mathrm{~W}-\mathrm{O}-\mathrm{W}$ & 893 & $\mathrm{~W} \mathrm{~W}_{3}$ \\
& & 861 & $\nu(\mathrm{W}-\mathrm{W}-\mathrm{O}-\mathrm{W})$ \\
& & 814 & $\gamma(\mathrm{W}-\mathrm{O}-\mathrm{W})$ \\
8 & $\mathrm{~W}-\mathrm{O}-\mathrm{W}$ & 700 & \\
\hline
\end{tabular}

a low frequency in-plane bending vibration $(\delta)$ is observable at $\sim 1630 \mathrm{~cm}^{-1}$ corresponding to $\mathrm{W}-\mathrm{OH}$ planes. These vibrational features get suppressed with $\mathrm{pH}$ reduction. It is possible that the sample prepared in a more acidic media provides us larger crystallites (as discussed before) with lower concentration of oxygen defects than that of the case of less acidic media. As a result, $v_{\text {sym }}\left(\mathrm{W}-\mathrm{OH} . . \mathrm{H}_{2} \mathrm{O}\right)$ and $\delta$ (W-OH) vibrations are affected. Apart from these, a strong stretching $v(\mathrm{~W}-\mathrm{O}-\mathrm{W})$ response in the inorganic compound itself is apparently visible at $\sim 814 \mathrm{~cm}^{-1}$. Note that in case of samples prepared in more acidic media (e.g. $\mathrm{pH}=3$ ) the mentioned vibration is accompanied by some asymmetric features owing to the presence of mixed phases like $\mathrm{W}_{3} \mathrm{O}_{9}$, $\mathrm{W}_{18} \mathrm{O}_{49}$ in the specimen.

\subsection{Electron microscopy studies}

Figure 5 represents TEM images of corresponding nanoscale $\mathrm{WO}_{3}$ samples prepared at $\mathrm{pH}=2,4$, and 5.5. As the medium of synthesis environment becomes more and more acidic, we found a gradual turn-over from the polyhedral morphology to fractal types. At $\mathrm{pH}=5 \cdot 5$, we observe regular polymorphs while the typical dimension of the polyhedral nanostructures vary in the range of $20-35 \mathrm{~nm}$ (figure 5a). The high resolution TEM image of an individual particle has revealed that the interplanar spacing among subsequent atomic planes is about $0.39 \mathrm{~nm}$ (figure $5 \mathrm{~b}$ ). The selective area electron diffraction (SAED) study, shown in the inset of figure 5(b), is characterized by three most prominent rings which designate (002), (020), (200); (112), (120); and (022), (202) planes in conformity with the XRD studies. The sample prepared at $\mathrm{pH}=4$ was found to result in assimilation of several polyhedrals (figure 5c). Interestingly, the specimen prepared at $\mathrm{pH}=2$ has revealed organizational bunching of nanostructures leading to fractals (figure 5d). Each of the small polyhedral units would join randomly but in a collective fashion leading to fractals. A fractal is a substance that displays self-similarity within a complicated system. As it appears, most of the sub-branch parts are connected to the main spine 

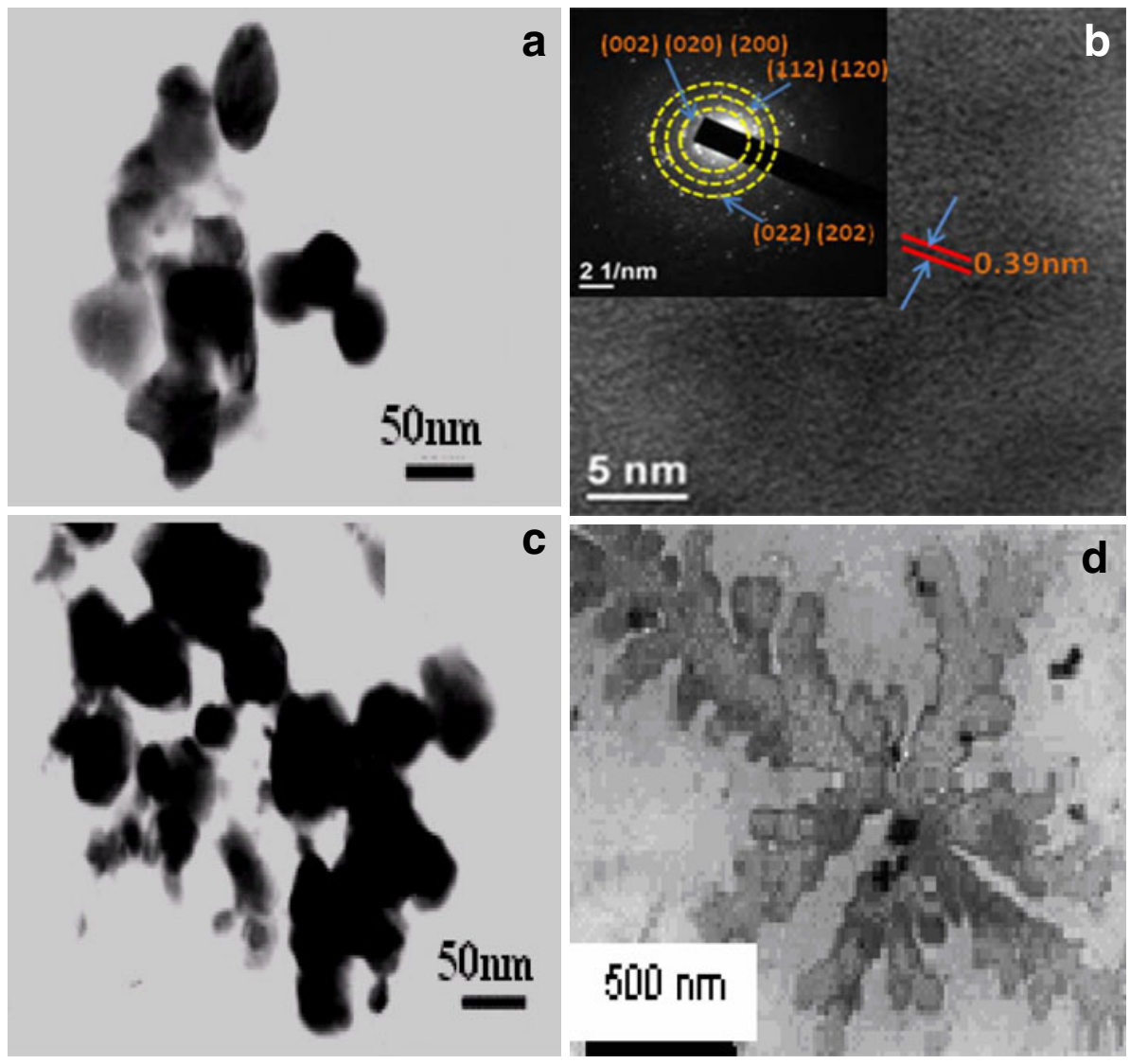

Figure 5. TEM micrographs of tungsten oxide nanostructures prepared at a. $\mathrm{pH}=5 \cdot 5$, c. $\mathrm{pH}=4$, and d. $\mathrm{pH}=2$. The high resolution TEM image of a single particle along with SAED response of sample $\mathbf{a}$ is shown in $\mathbf{b}$.

and pointing radially outward from the core (figure $5 \mathrm{~d}$ ). In fact, the specimen corresponding to $\mathrm{pH}=4$ has witnessed the initial stage of directional growth for building up fractals at low $\mathrm{pH}$. The question is why and how? As already discussed in XRD analysis, the higher value of $\mathrm{pH}$ supports competitive growth of (002), (020), and (200) planes. As the nanocrystallite growth is significantly affected by the intercalated water molecules, in acidic environment, the symmetric growth of these planes is drastically hindered. Further, the use of cationic surfactant like CTAB will not be able to protect individual nanoparticles from the excess supply of $\mathrm{H}^{+}$ions. In the present case (for $\mathrm{pH}=2$ ), growth along (020) and (200) planes is suppressed considerably, whereas growth along (002) plane is still favoured. In a strong acidic environment, simultaneous growth of crystallites can be associated with diffusion limited aggregation leading to fractal patterns.

\subsection{Raman spectroscopy studies}

Raman spectra of $\mathrm{WO}_{3}$ samples, synthesized at $\mathrm{pH}=2,4$, and 5.5 are depicted in figure 6 . All the spectra were characterized by two well-developed peaks, corresponding to transverse optic (TO) and longitudinal optic (LO) modes which

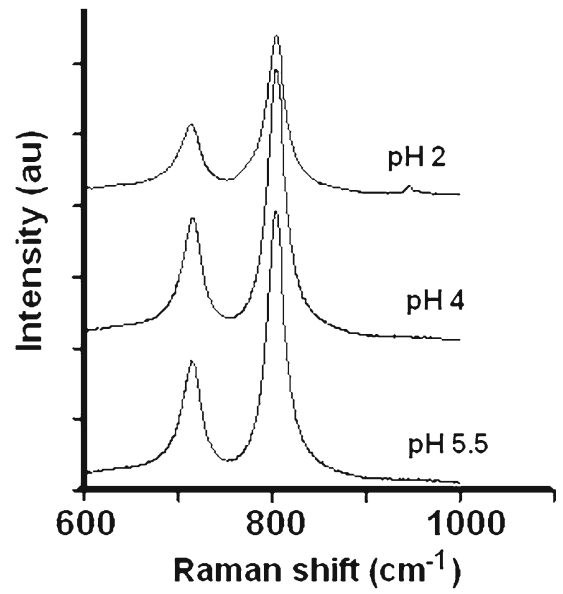

Figure 6. Raman spectra of nanoscale $\mathrm{WO}_{3}$ particles prepared at $\mathrm{pH}=2, \mathrm{pH}=4$, and $\mathrm{pH}=5 \cdot 5$.

were observable at 717 and $805 \mathrm{~cm}^{-1}$, respectively. In fact, these $\mathrm{TO}$ and $\mathrm{LO}$ modes are representative of the monoclinic$\gamma$-phase of $\mathrm{WO}_{3}$ (Deshpande et al 2007). Earlier it was argued that phonon confinement effects can be observed on 
the major phonon band at $800 \mathrm{~cm}^{-1}$ assigned to the $\mathrm{O}-\mathrm{W}-$ $\mathrm{O}$ stretching mode and to $\mathrm{W}^{6+}=\mathrm{O}$ surface dangling bonds (Grabrusenoks et al 2001; Huang et al 2002; Adu et al 2006). As discussed earlier, the formation of monoclinic tungsten oxide also agree with the XRD and FTIR spectroscopy studies. Thus one can ensure that the nanoparticle samples comprise largely of $\mathrm{WO}_{3}$ phase. The LO to TO Raman intensity signal bears a constant value of $2 \cdot 2$. For our nanoscale $\mathrm{WO}_{3}$ systems, the respective FWHM for TO and LO modes are 19 and $29 \mathrm{~cm}^{-1}$; whereas for bulk $\mathrm{WO}_{3}$ the FWHM was predicted to be $\sim 6.5 \mathrm{~cm}^{-1}$ (Adu et al 2006). The fairly broadened XRD diffraction as well as Raman active peaks are due to small nanocrystallite size and possibly, introduction of certain amount of disorder in the system owing to $\mathrm{pH}$ variation. The Raman spectra, however, did not indicate the presence of $\mathrm{WO}_{2}$ crystallites whose optical phonon peaks are generally located at $617,781 \mathrm{~cm}^{-1}$ (Frey et al 2001). Being the monoclinic- $\gamma$-phase of $\mathrm{WO}_{3}$ as the most stable phase, the $\mathrm{WO}_{3}$ Raman active peaks not only prohibit the detection of low concentration of $\mathrm{WO}_{2}$ but also remain in tact with regard to structure and symmetry for all the synthesized samples.

\subsection{Thermochromic properties}

Thermochromic process describes colour change phenomena associated with temperature. In order to study ther- mochromic properties of the nanoscale $\mathrm{WO}_{3}$ product $(\mathrm{pH}=$ $5 \cdot 5$ ), we suspended the product in deionized water and then transferred the resulting solution into a petriplate thus forming a thin surface layer at the base. The snapshots were captured while the petriplate was kept at $4^{\circ} \mathrm{C}, 15^{\circ} \mathrm{C}, 27^{\circ} \mathrm{C}$, $40^{\circ} \mathrm{C}$ and finally at $53^{\circ} \mathrm{C}$ (figure 7). The transient colour change from super-white to light-brown, and to milky-white was noticed as one moves through lowest $\left(4^{\circ} \mathrm{C}\right)$ and highest temperature $\left(53^{\circ} \mathrm{C}\right)$. This clearly depicts thermochromism induced by the temperature of the external environment. In order to make a clear analysis on what we observed, we have selected the central region in each of the digital snapshots and obtained the brightness feature using standard MATLAB ${ }^{\circledR}$ program the results of which (i.e., luminosity vs temperature response) is depicted in figure $7(\mathrm{a}, \mathrm{b})$. Higher luminosity corresponds to higher brilliance whereas lower luminosity values would represent dull features. The luminosity is found to be minimum around room temperature $\left(27^{\circ} \mathrm{C}\right)$ whereas relatively higher intensity was observed at the extreme ends. This would be definitely interesting while making temperature sensitive devices that are required to work at lower and higher than room temperature. To summarize, nanoparticle size-dependent thermochromic studies would help in assessing efficiency of the particular thermochromic device/component. Size-dependent thermochromic behaviour of organic polymer based nanosystems has already been reported (Kurokawa et al 2004).
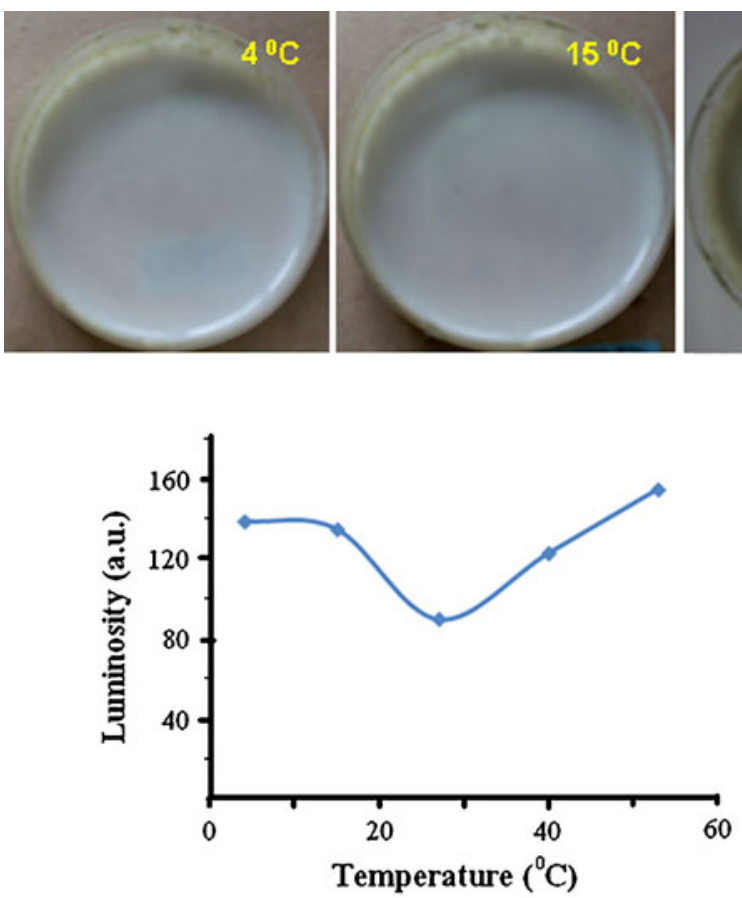

(a)
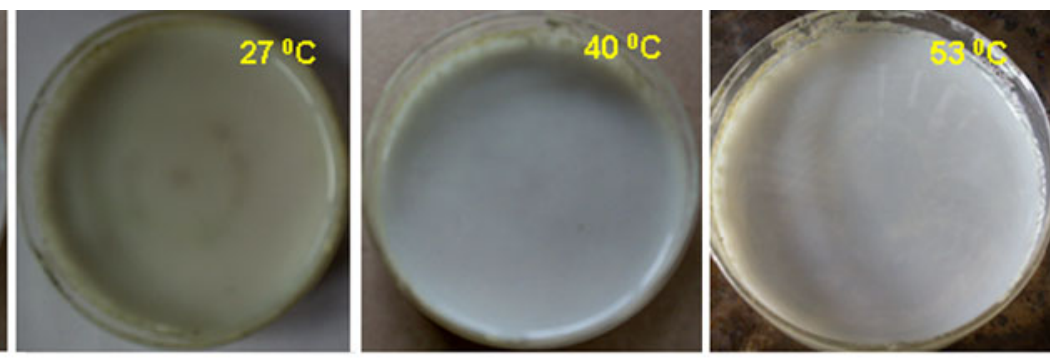

" Temperature $\left({ }^{\circ} \mathrm{C}\right) \quad$ - Luninosity (a.u.)

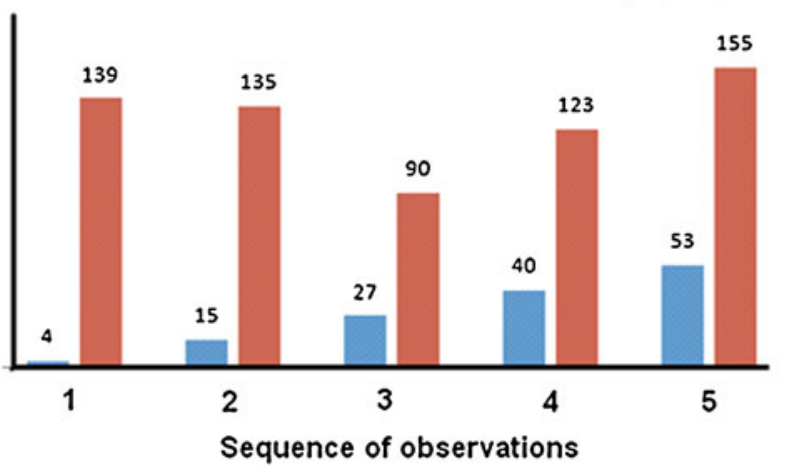

(b)

Figure 7. Thermochromic effect of nanoscale $\mathrm{WO}_{3}$ in $d / d$ water spread on petriplates at different temperatures (upper part). In lower part, the luminosity vs. temperature response is shown in (a). The thermochromic response is represented by corresponding histograms in (b). 


\subsection{Photochromic properties}

The colouration phenomena stimulated by photons is defined as photochromism. Alternatively, photochromism is a reversible colouration phenomena induced by a transformation of the chemical species between two forms by the absorption of electromagnetic radiation. Earlier, photochromic response of $\mathrm{MoO}_{3}$ nanoparticles as well as that of $\mathrm{Ag}$ nanoparticle-loaded $\mathrm{TiO}_{2}$ films have been demonstrated (Yao et al 1992; Naoi et al 2004). Three laser sources (green: $\lambda=543 \mathrm{~nm}$, orange: $\lambda=594 \mathrm{~nm}$, and red: $\lambda=632 \mathrm{~nm}$ ) and three different concentrations of $\mathrm{WO}_{3}(\mathrm{pH}=5.5$ case $)$ i.e. $0.2,0.4$, and $0.6 \mathrm{mg} / \mathrm{ml}$ were used in the experiment. The light beam was allowed to pass through a cuvette containing sample specimen while the transmitted light was collected by a photodetector on the other side of the sample specimen. Both the wavelength and nanoparticle concentration dependent transmission responses were recorded which are presented in figure $8(\mathrm{a}, \mathrm{b})$. As a general trend, corresponding to a definite incident wavelength, we find significant drop in the transmission as concentration was increased from 0.2 to $0.6 \mathrm{mg} / \mathrm{ml}$. Further, for a given concentration, the transmission response has substantially increased with increase in incident wavelength. For instance, in case of a concentration value of $0.6 \mathrm{mg} / \mathrm{ml}$, the transmission response is apparently enhanced from $25 \%$ to $29 \%$ as wavelength of the incident radiation is increased from $543 \mathrm{~nm}$ to $632 \mathrm{~nm}$. In order to measure the wavelength of the emergent beams, we used the conventional relation (Hummel 1997):

$$
\lambda_{T}=\frac{\lambda_{I}}{T}
$$

with $\lambda_{I}$ and $\lambda_{T}$ representing incident and transmitted wavelengths and $T$ being transmittance. Using the transmitted responses for different nanoparticle concentrations, the $\lambda_{T}$ values can be estimated and a plot in this regard is presented in figure 8(c). As can be observed, for $0.2 \mathrm{mg} / \mathrm{ml}$ conc., with an incident wavelength variation between 543 and $632 \mathrm{~nm}$ the transmitted light wavelength changes in the range of 976-1074 nm. Higher transmitted wavelengths are noticeable for higher particle concentration and exhibits a saturation trend beyond a critical limit. In case of intense illumination (field strength $>10^{6} \mathrm{~V} / \mathrm{cm}$ ) on nanosystems, one can think of obtaining harmonics with lower and higher wavelengths (nonlinear optical phenomena) that largely depend on the initial condition and the nature of photon-matter interaction. In our case, however, we expect higher absorption for higher concentration of particles as a result of which transmission response in the output decreases. It is also expected that part of the incident photon energy is being used in altering the oxidation state of $\mathrm{W}$ temporarily. Consequently, the emergent photons will have lower energy (higher wavelength) than incident ones. Previously, colouration mechanism was described in terms of creation of F centres, dipolaron injection, and simultaneous injection of electrons and
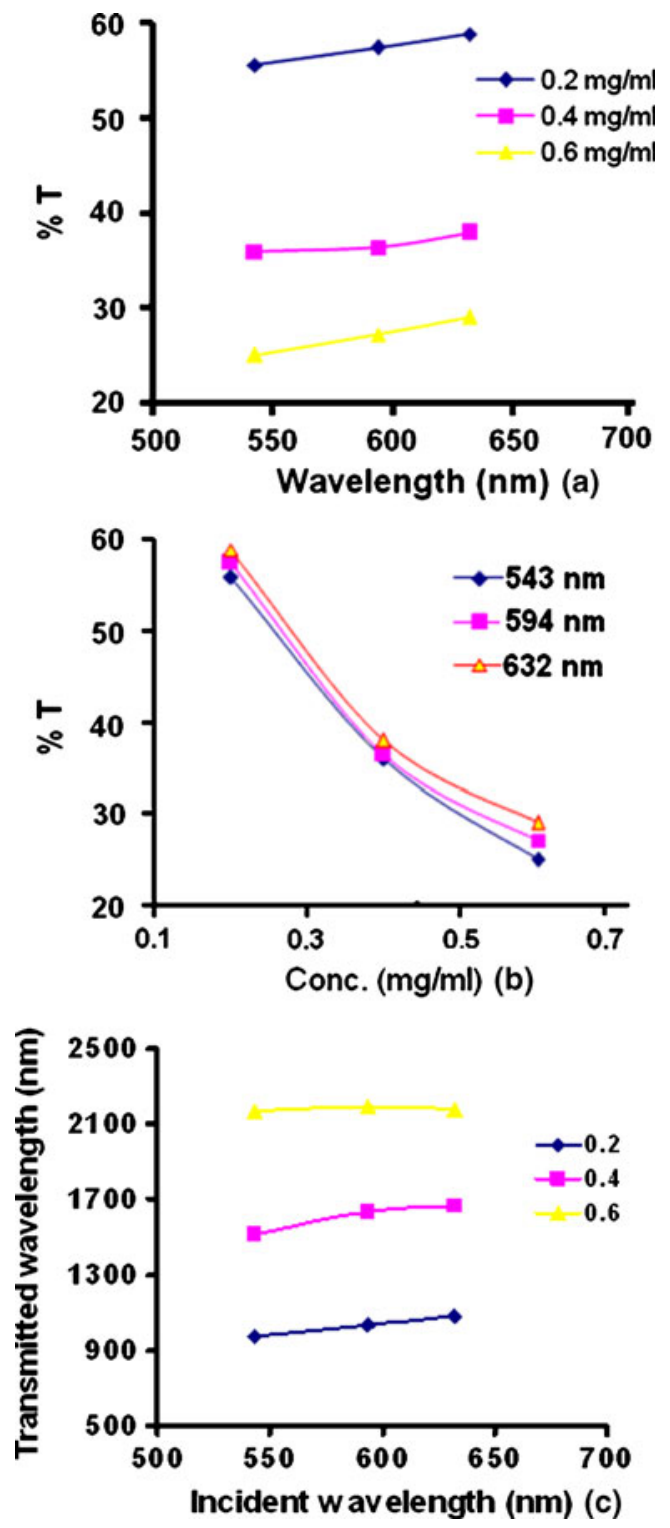

Figure 8. Photochromic effect of tungsten oxide nanoparticles $(\mathrm{pH}=5 \cdot 5)$. Here, (a) and (b) depict transmission response w.r.t. incident wavelength and concentration variation, respectively. Transmitted wavelength vs incident one is shown in (c).

cations (Faughnan et al 1975; Schirmer and Salje 1980). All the described mechanisms have their own merits and limitations. In a recent work, an appreciable photochromism was demonstrated in $\mathrm{Mn}$ incorporated $\mathrm{ZnO}$ nanosystems (Misra et al 2008). At present, it is difficult to predict a suitable model that fits well to our system, but we expect that the overall cause is due to the transitory variation of the oxidation state of $\mathrm{W}$ as a result of absorption of em radiation by the tungsten oxide system. Similarly, localized defects and dislocations can also be responsible for the formation of $e-h$ pairs in the excitation process and forming colour centres through trapping of free carriers. Earlier, electrochromic response of $\mathrm{WO}_{3}$ nanoparticles was assigned to a sub-stoichiometric 
(oxygen deficient) state of $\mathrm{WO}_{3}$ (Deshpande et al 2007). Exhibiting reversible phenomena, the material would regain its original state when taken back to dark.

Most of the photochromic glass-making industries use colour pigments. Embedment of different sized photochromic material into glass can be an alternative approach. In view of this, tungsten oxide nanoparticles will probably be the finest candidates for application in attractive toys, glasses and smart windows that principally rely on thermochromic, photochromic and electrochromic processes.

\section{Conclusions}

The role of $\mathrm{pH}$ in determining a definite tungsten oxide nanostructure is discussed. The XRD analysis predicts the co-existence of both monoclinic and triclinic phases but to different amounts. It was also suggested that stronger acidic media can result in branched nanostructures (fractals). Raman studies have revealed highly symmetric peaks which were attributed to TO and $\mathrm{LO}$ modes of $\mathrm{WO}_{3}$ and are in consistency with others work. The thermochromic study within $4-53^{\circ} \mathrm{C}$ describes a clear colouration phenomena induced by heat. The photochromic response shows that transmission response would decrease with increase in nanoparticle concentration and incident wavelength. Consequently, large emergent wavelength can be momentarily achieved out of incident light of smaller wavelengths. A size dependent colouration study followed by careful modeling will bring new insight to this metal oxide system.

\section{Acknowledgements}

We thank the Department of Chemical Sciences, TU, for supplying us with sodium tungstate and extending help in FT-IR measurements. We also extend our sincere thanks to SAIFNEHU, Shillong and IIT Guwahati, for providing TEM and HRTEM measurements, respectively.

\section{References}

Adu K W, Gutierrez H R and Eklund P C 2006 Vib. Spectrosc. 42 165

Agiral A and Gardeniers J G E 2008 J. Phys. Chem. C 11215183

Atanassor G, Thielsch R and Popor D 1993 Thin Solid Films 223 288
Bailar J C and Emeleus H J 1973 Comput. Inorg. Chem. 3742

Deshpande R et al 2007 Solid State Ionics 178895

Engweiler J, Harf J and Baiker A 1996 J. Catal. 159259

Faughnan B W, Crandall R S and Heyman P M 1975 RCA Rev. 36 177

Frey G L, Rothschild A, Sloan J, Rosentsveig R, Popovitz-Biro R and Tenne R 2001 J. Solid State Chem. 162300

Grabrusenoks J et al 2001 J. Electrochim. Acta 462229

Granqvist C G 2000 Solar Ener. Mater. Solar Cell 60201

Hagfeldt A and Gratzel M 1995 Chem. Rev. 9549

Hargittai I, Hargittai M, Spiridonov V P and Erokhin E V $1971 \mathrm{~J}$. Mol. Struct. 831

Henglein A 1989 Chem. Rev. 891861

He T, Ma Y, Cao Y, Hu X, Liu H, Zhang G, Yang W and Yao J 2002 J. Phys. Chem. B 10612670

Huang Y S, Zhang Y Z, Zeng X T and Hu X F 2002 Appl. Surf. Sci. 202104

Hummel R I 1997 Handbook of optical properties: Optics of small particles, interfaces and surfaces I (New York: CRC Press)

Jimenez I, Arbiol J, Dezanneau G, Cornet A and Morante J R 2003 Sens. Actuat. B 93503

Kang H 2004 J. Nucl. Mater. 3351

Kurokawa N, Yoshikawa H, Hirota N, Hyodo K and Masuhara H 2004 Chem Phys. Chem. 51609

Lee D S, Nam K H and Lee D D 2000 Thin Solid Films 375142

Lee K, Seo W S and Park J T 2003 J. Am. Chem. Soc. 1253408

Leland J K and Bard A J 1987 J. Phys. Chem. 915083

Lethy K J, Pandya S, Beena D, Vinodkumar R, Sathe V and Pillai V P M 2009 J. Phys. D: Appl. Phys. 42185407

Li S T, Germanenko I N and Ei-Shall M S 1998 J. Phys. Chem. B 1027319

Madou M J and Morrison S R 1989 Chemical sensing with solid state devices (San Diego: Academic Press)

Misra N, Roy M, Mohanta D, Baruah K and Choudhury A 2008 Cent. Eur. J. Phys. 6109

Naoi K, Ohko Y and Tatsuma T 2004 J. Am. Chem. Soc. 126 3664

Noh W, Shin Y, Kim J, Lee W, Hong K, Akbar S A and Park J 2002 Solid State Ionics 152827

Pfeifer J, Guifang Cao, Tekula-Buxbaum P, Kiss B A, FarkasJahnke M and Vadasdi K 1995 J. Solid State Chem. 11990

Raougier A, Portemer F, Quede A and El Marssi M 1999 Appl. Surf. Sci. 1531

Schirmer Y O F and Salje E 1980 J. Phys. C 13 L1067

Selcuk C, Bentham R, Morley N and Wood J V 2004 Mater. Lett. 581873

Sun M, Xu N, Cao Y W, Yao J N and Wang E G 2000 J. Mater. Res. 15927

Wang F-Z, Zhang H, Ding B-J and Zhu R-H 2002 Mater. Sci. Eng. A 33659

Williamson G K and Hall W 1953 Acta Metall. 122

Yao J N, Hashimoto K and Fujishima A 1992 Nature 355624 